\title{
DIREITO SUCESSÓRIO DOS ASCENDENTES NA \\ MULTIPARENTALIDADE
}

\section{INHERITANCE LAW OF ASCENDANTS IN MULTIPARENTALITY}

Área: Direito Civil. Família.

\section{Flávia Squincalha ${ }^{1}$}

RESUMO: O presente trabalho apresenta uma análise do direito sucessório em casos de multiparentalidade, uma lacuna do ordenamento jurídico brasileiro. Tem como objetivo demonstrar a possibilidade e os principais efeitos jurídicos da multiparentalidade, sendo abordado o modo como o assunto foi tratado pelos Tribunais Superiores, até chegar ao Supremo Tribunal Federal, que pôs fim à polêmica. Tendo em vista que, agora, a referida decisão servirá de sustentação para a execução de tal direito em todo o país, surgem inúmeras indagações devido às lacunas legais. Assim, buscou-se ressaltar e estudar, por meio de exploração de uma intensa bibliografia, os problemas e as possíveis interpretações que trazem as soluções mais adequadas para situações em que haja mais de um vínculo paterno ou materno. Observando a evolução do conceito de família, bem como o surgimento de diferentes formas de vínculos familiares, em um futuro próximo, operadores do Direito deparar-se-ão com inventários baseados em tais conflitos. Logo, diante de tantas inovações, faz-se necessário o presente estudo, para busca pelo melhor entendimento à esfera de sucessões.

PALAVRAS-CHAVE: Sucessão. Ascendentes. Multiparentalidade. Afetividade.

ABSTRACT: This work presents an analysis of inheritance law in multiparenting cases, a gap in the Brazilian legal system. It aims to demonstrate the possibility and the main legal effects of multiparenting, by addressing the way the matter was dealt with by the Superior Courts, until it reached the Supreme Federal Court, which ended the controversy. Once this decision will now support the enforcement of such a right across the country, numerous questions arise due to legal shortcomings. Thus, we sought to highlight and study, through exploration of an intense bibliography, the

Advogada. Pós-graduada em Direito e Agronegócio. 
problems and possible interpretations that bring the most appropriate solutions for situations in which there is more than one paternal or maternal bond. Observing the evolution of the concept of family, as well as the emergence of different forms of family bonds, in the near future, legal operators will come across inventories based on such conflicts. Therefore, in view of so many innovations, this study is necessary to seek a better understanding of the sphere of successions.

KEYWORDS: Succession. Ascendants. Multiparenting. Affectivity.

SUMÁRIO: Introdução. 1. Direito Das Famílias E A Socioafetividade. 2. Os Fundamentos Do Direito Sucessório. 2.1 Função Social Da Herança. 2.2 As Modalidades De Herdeiros Do Código Civil. 2.3 Sucessão Legítima E Parentesco. 3. O Direito À Sucessão Dos Ascendentes Em Caso De Multiparentalidade. 3.1 Lacuna Legal. Considerações finais. Referências Bibliográficas.

\section{Introdução}

O Direito de família é regido por normas essencialmente de ordem pública, visto que está intimamente ligado ao direito existencial, sendo nula qualquer previsão de renúncia a esses direitos, como disposto nos artigos 1.511 a 1.638, do Código Civil; por outro lado, também há normas de caráter privado, tendo como exemplo aquelas relacionadas ao regime de bens, de cunho patrimonial, trazidas pelos artigos 1.639 a 1.688 do Código Civil.

Historicamente, a família possuiu funções diversas - religiosa, econômica e reprodutiva -, permanecendo sob modelo estático, imposto por uma sociedade conservadora e paternalista por muito tempo; no entanto, a sociedade e as famílias passaram por inúmeras e profundas alterações, e, consequentemente, este ramo do Direito sentiu necessidade de evolução.

Uma dessas evoluções foi o acolhimento - por parte do Tribunal Pleno do Supremo Tribunal Federal - da multiparentalidade, já que a existência de uma paternidade socioafetiva não deve prejudicar o filho de buscar ou ter relação com sua paternidade biológica e, assim, ser sujeito passivo de todos os direitos e obrigações decorrentes dessa ligação. O novo entendimento sobre família passa a se embasar no princípio da dignidade, na valorização do próprio indivíduo e sua afetividade com os que constituem seu lar, fazendo do afeto o elo que une o indivíduo à sua família, independentemente de vínculo sanguíneo.

Apesar de muito se falar em parentalidade socioafetiva, pouco se 
exploram os efeitos por ela gerados. Ao longo do trabalho, será trazido o que ocorre, caso o filho venha a falecer antes dos pais, sem que tenha deixado descendentes. A solução para tal questionamento sempre foi que os ascendentes da linha paterna herdem a metade, cabendo a outra metade aos da linha materna. Ou seja, o pai recebia a metade dos bens, e a mãe a outra metade. Em caso de multiparentalidade, por analogia ao disposto no artigo supracitado, a mãe recebe metade, e cada pai tem direito a um quarto da herança? Ou a melhor alternativa seria a distribuição de um terço da herança aos ascendentes?

A resposta à questão trazida pelo Código Civil atual, que disciplina o assunto, logicamente, não pode ser desconsiderada, tendo em vista que ninguém será obrigado a fazer ou deixar de fazer alguma coisa senão em virtude de lei, conforme o princípio da legalidade. Será demonstrado, assim, que a regra continuaria em situações de reconhecimento de multiparentalidade.

Destarte, neste trabalho, será trazido o reconhecimento - por nossos tribunais - do princípio da afetividade, tratando-se de um elo de parentesco civil, sem vínculo biológico, mas que, em decorrência da forte ligação de afeto, vivem como se parentes fossem. Esse tornou-se o princípio guia para os novos conceitos de família. Além do mais, será destacado o tratamento que as Cortes Superiores têm dado ao vínculo socioafetivo, que vai além do vínculo adotivo, simplesmente. E, por último, a interpretação da tese da multiparentalidade, a possibilidade de se possuir, com regulamentação legal, mais de um pai ou uma mãe e os efeitos decorrentes de tal relação, com ênfase no direito sucessório.

\section{Direito das famílias e a socioafetividade}

Os antigos princípios de Direito de Família foram exterminados, surgindo outros, de acordo com uma proposta de constitucionalização. A horizontalização das normas que protegem as pessoas assume a necessidade de serem aplicadas entre os particulares, como os princípios fundamentais da dignidade humana e solidariedade familiar, da igualdade de filhos, de gêneros e da equivalência das entidades familiares.

Sobre os princípios norteadores do novo direito das famílias, enuncia o artigo $1^{\circ}{ }^{\circ}$, inciso III, da Constituição Federal de $1988^{2}$, que nosso Estado tem como princípio fundamental a dignidade de pessoa humana, um superprincípio. Ingo Wolfgang Sarlet conceitua o princípio em questão como:

O reduto intangível de cada indivíduo e, neste sentido, a última fronteira contra

BRASIL. Constituição da República Federativa do Brasil de 1988. Casa Civil.

128 • Themis Revista Jurídica • Volume 02 • Número 03 • Jan-Dez 2021 
quaisquer ingerências externas. Tal não significa, contudo, a impossibilidade de que se estabeleçam restrições aos direitos e garantias fundamentais, mas que as restrições efetivadas não ultrapassem o limite intangível imposto pela dignidade da pessoa humana. ${ }^{3}$

A dignidade está dentro de cada um, sendo o Direito das Famílias o ramo mais humano de todo o Direito. Nesse sentido, a Declaração Universal dos Direitos Humanos traz, em seu preâmbulo, que o reconhecimento da dignidade deve ser inerente a todos os membros da família humana e de seus direitos iguais e inalienáveis, como fundamento da liberdade, da justiça e da paz no mundo. No que concerne à lesão da dignidade humana, apresenta-se um relevante julgado, do Tribunal de Alçada Civil de Minas Gerais, sobre o caso Alexandre Fortes cuja ementa faz referência expressa a esse princípio:

Indenização por danos morais. Relação paterno-filial. Princípio da dignidade da pessoa humana. Princípio da afetividade. A dor sofrida pelo filho, em virtude do abandono paterno, que o privou do direito à convivência, ao amparo afetivo, moral e psíquico, deve ser indenizável, com fulcro no princípio da dignidade da pessoa humana (Tribunal de Alçada de Minas Gerai, $7^{\text {a }}$ Câmara de Direito Privado, Apelação Cível 408.555-5, decisão 01.04.2004, Rel. Unias Silva, v.u.).

Lamentavelmente, a decisão que condenou o pai ao pagamento de danos morais ao filho foi reformada pelo Superior Tribunal de Justiça, no ano de 2005; entretanto, demonstrando evolução em relação ao tema, em 2012, o Superior Tribunal de Justiça, em revisão ao acórdão supracitado, admitiu a reparação civil pelo abandono afetivo, por meio do Informativo n. 496 do STJ:

\begin{abstract}
CIVIL E PROCESSUAL CIVIL. FAMÍLIA. ABANDONO AFETIVO. COMPENSAÇÃO POR DANO MORAL. POSSIBILIDADE. 1. Inexistem restrições legais à aplicação das regras concernentes à responsabilidade civil e o consequente dever de indenizar/compensar no Direito de Família. 2.. (...) 4. Apesar das inúmeras hipóteses que minimizam a possibilidade de pleno cuidado de um dos genitores em relação à sua prole, existe um núcleo mínimo de cuidados parentais que, para além do mero cumprimento da lei, garantam aos filhos, ao menos quanto à afetividade, condições para uma adequada formação psicológica e inserção social. 5. A caracterização do abandono afetivo, a
\end{abstract}

SARLET, Ingo Wolfgang A eficácia dos direitos fundamentais. 5. ed. Porto Alegre: Livraria do Advogado, 2005. p. 124. 
existência de excludentes ou, ainda, fatores atenuantes (...) não podem ser objeto de reavaliação na estreita via do recurso especial. 6. A alteração do valor fixado a título de compensação por danos morais é possível, em recurso especial, nas hipóteses em que a quantia estipulada pelo Tribunal de origem revela-se irrisória ou exagerada. 7. Recurso especial parcialmente provido. (STJ, REsp 1.159.242/ SP, Rel. Min. Nancy Andrighi, $3^{\mathrm{a}}$ Turma, j. 24.04.2012, DJe 10.05.2012).

O acórdão proferido pela Corte demonstra a concretização jurídica da dignidade humana, visando a evitar o abandono nas famílias. Por sua vez, o princípio da solidariedade familiar ficou reconhecido pelo artigo $3{ }^{\circ}$, inciso I, da Constituição Federal de 1988. Paulo Lôbo, sobre o princípio em pauta, ensina:

A solidariedade, como categoria ética e moral que se projetou para o mundo jurídico, significa um vínculo de sentimento racionalmente guiado, limitado e autodestinado que compele à oferta de ajuda, apoiando-se em uma mínima similitude de certos interesses e objetivos, de forma a manter a diferença entre os parceiros na solidariedade... O princípio da solidariedade vai além da justiça cumulativa, da igualdade formal, pois projeta os princípios da justiça distributiva e da justiça social. Estabelece que a dignidade de cada um apenas se realiza quando os deveres recíprocos de solidariedade estão observados ou aplicados. ${ }^{4}$

O princípio da solidariedade, quando trazido para o âmbito familiar, se trata de assistência, cooperação, proteção e cuidado mútuo, agora, com valor jurídico. Nos termos do artigo 226, $\S 8 .^{\circ}$, da nossa Carta Maior, "o Estado assegurará a assistência à família na pessoa de cada um dos que a integram, criando mecanismos para coibir a violência no âmbito de suas relações". Esse preceito estimula a compreensão da família brasileira contemporânea que, após a liberdade alcançada, tem que lidar com a complexidade dos vínculos familiares criados.

Quando a Constituição Federal se refere à solidariedade, faz menção, obviamente, à base da sociedade, que é justamente a família! Outro princípio indispensável ao Direito de família é o que diz respeito à igualdade entre os filhos. O artigo 1.593 do Código Civil estabelece: "O parentesco é civil ou natural, conforme resulte da consanguinidade ou outra origem."; assim, com base no dispositivo legal, é possível, efetivamente, que o conceito de família se estenda e seja interpretado de modo amplo, conforme corrobora o enunciado

\footnotetext{
4 LÔBO, Paulo. Princípio da Solidariedade Familiar. 2013. p. 01-02. Disponível em https://jus. com.br/artigos/25364/principio-da-solidariedade-familiar. Acesso em: 23 maio 2019.
} 
256, do Conselho de Justiça Federal, que dispõe que "a posse do estado de filho (parentalidade socioafetiva) constitui modalidade de parentesco civil."

Por sua vez, o artigo 227, $\S 6^{\circ}{ }^{\circ}$, da Constituição Federal, determina que "os filhos, havidos ou não da relação de casamento, ou por adoção terão os mesmo direitos e qualificações, proibidas quaisquer designações discriminatórias relativas à filiação". Maria Berenice Dias também discorreu sobre o tema em sua obra:

A supremacia do princípio da igualdade alcançou também os vínculos de filiação, ao proibir qualquer designação discriminatória com relação aos filhos havidos ou não da relação de casamento ou por adoção. Em boa hora o constituinte acabou com abominável hipocrisia que rotulava a prole pela condição dos pais. A postura do genitor que descumpria o dever de fidelidade e cometia o crime de adultério era premiada, pois não lhe gerava obrigações com relação ao filho assim concebido. ${ }^{5}$

O princípio da igualdade entre os filhos rompeu a constituição formal de uma entidade familiar, nas palavras de Dimas Messias de Carvalho, "desbiologizando a paternidade"; assim, sob a ótica familiar, trata-se do mais importante princípio para alcançar a isonomia constitucional; outrossim, é imprescindível dizer, após o princípio da igualdade entre os filhos, sobre o princípio da igualdade entre cônjuges e companheiros. Nesse cenário, dispõe o artigo 226, § 3. ${ }^{\circ}$, da Constituição Federal: "Para efeito da proteção do Estado, é reconhecida a união estável entre o homem e a mulher como entidade familiar, devendo a lei facilitar sua conversão em casamento".

Logo, em observância aos princípios da igualdade, dignidade da pessoa humana e da vedação ao retrocesso, equiparou-se o regime sucessório da união estável com o do casamento, determinando a aplicação, tanto em um, quanto em outro, das regras da sucessão legítima, dispostas no artigo 1.829, do Código Civil; desse modo, o companheiro ou cônjuge sobrevivente poderá concorrer com os descendentes do de cujus, a depender do regime de bens adotado para a união estável; sempre concorrerá com os ascendentes e, ainda, se não houver nem descendentes, nem ascendentes, concorrerá sozinho com toda a herança, não alcançando os colaterais, a sucessão.

Em decorrência do princípio da igualdade entre os cônjuges e companheiros, surge o princípio da igualdade na chefia familiar, que estabelece

DIAS, Maria Berenice. Amor não tem idade. Portal Jurídico Investidura, Florianópolis/SC, 12 Jan. 2009. p. 1. 
que não há distinção entre homem e mulher, e a liderança pode-se concentrar tanto em um, quanto em outro, sendo válido, ainda, a manifestação da prole. $\mathrm{O}$ artigo 1.566, do Código Civil, evidencia esse princípio ao estabelecer como deveres de ambos os cônjuges, além mútua assistência, o sustento, a guarda e educação dos filhos e o respeito e consideração mútuos. A evolução do Direito das famílias suprimiu a figura autoritária masculina e a subordinação em relação aos demais integrantes do grupo familiar, encontrando-se, na contemporaneidade, em grau igualitário.

Avançando o tema, é fundamental explanar sobre o princípio da função social da família, haja vista que o artigo 226, caput, da nossa Carta Constitucional, dispõe que família é a base da sociedade, tendo especial proteção do Estado; destarte, as famílias merecem especial atenção, conforme ensinam Pablo Stolze Gagliano e Rodolfo Pamplona Filho:

Numa perspectiva constitucional, a funcionalização social da família significa o respeito ao seu caráter eudemonista, enquanto ambiência para a realização do projeto de vida e de felicidade de seus membros, respeitando-se, com isso, a dimensão existencial de cada um...A principal função da família é a sua característica de meio para a realização de nossos anseios e pretensões. ${ }^{6}$

Logo, não reconhecer a função social da família é como não reconhecer a própria sociedade. Por fim, para enlaçar todos os princípios explanados, é imprescindível discorrer sobre o princípio da afetividade, apontado como a base das relações familiares, em decorrência da dignidade de pessoa humana. Em relação a tal princípio, merecem destaque os ensinamentos de Giselle Câmara Groeninga:

O papel dado à subjetividade e à afetividade tem sido crescente no Direito de Família, que não mais pode excluir de suas considerações a qualidade dos vínculos existentes entre os membros de uma família, de forma que possa buscar a necessária objetividade na subjetividade inerente às relações. Cada vez mais se dá importância ao afeto nas considerações das relações familiares; aliás, um outro princípio do Direito de Família é o da afetividade. ${ }^{7}$

Em sede de Direito Comparado, a Suprema Corte do Estado da Louisiana,

GAGLiAnO, Pablo Stolze; PAMPlONA FILHO, Rodolfo. Novo Curso de Direito Civil: Direito de Família. 7. ed. São Paulo: Saraiva, 2011, v. 06.

7 GROENINGA, Giselle Câmara. Direito Civil. Direito de Família. v. 7. São Paulo: RT, 2008. p. 28.

132 • Themis Revista Jurídica • Volume 02 • Número 03 • Jan-Dez 2021 
nos Estados Unidos, julgou o recurso 553 So.2d 847, 848 e reconheceu a dupla paternidade no caso Smith v. Cole (Dual Paternity In Louisiana), do ano de 1989, o que abriu portas para as decisões legislativas no sentido de se alterar a lei civil, a fim de reconhecer e positivar a multiparentalidade, em 2005. A promoção e a proteção da unidade familiar foram as principais razões para esse reconhecimento, tornando remoto o tratamento historicamente severo de crianças ilegítimas por parte de Louisiana.

O Supremo Tribunal Federal, por sua vez, no ano de 2016, aprovou tese no sentido de que a paternidade socioafetiva não impede o reconhecimento do vínculo de filiação baseada na origem biológica, com os efeitos jurídicos próprios, independentemente de registro, afirmando, ainda, que a paternidade socioafetiva não representa uma paternidade de segunda ordem em relação à biológica, abrindo caminho para a multiparentalidade expressa no Provimento 63 do Conselho Nacional de Justiça (CNJ):

EMENTA - Institui modelos únicos de certidão de nascimento, de casamento e de óbito, a serem adotadas pelos ofícios de registro civil das pessoas naturais, e dispõe sobre o reconhecimento voluntário e a averbação da paternidade e maternidade socioafetiva no Livro "A" e sobre o registro de nascimento e emissão da respectiva certidão dos filhos havidos por reprodução assistida.

...Art. 10. O reconhecimento voluntário da paternidade ou da maternidade socioafetiva de pessoa de qualquer idade será autorizado perante os oficiais de registro civil das pessoas naturais.

$[\ldots]$

Art. 11. O reconhecimento da paternidade ou maternidade socioafetiva será processado perante o oficial de registro civil das pessoas naturais, ainda que diverso daquele em que foi lavrado o assento, mediante a exibição de documento oficial de identificação com foto do requerente e da certidão de nascimento do filho, ambos em original e cópia, sem constar do traslado menção à origem da filiação.

$[\ldots]$

Art. 14. O reconhecimento da paternidade ou maternidade socioafetiva somente poderá ser realizado de forma unilateral e não implicará o registro de mais de dois pais e de duas mães no campo FILIAÇÃO no assento de nascimento. ${ }^{8}$

O Colégio de Coordenadores da Infância e Juventude dos Tribunais de Justiça do Brasil pediu a tomada de providências (0001711-40.2018.2.00.0000),

CNJ. Conselho Nacional de Justiça. Provimento n. 63 de 14 de novembro de 2017. 
no sentido de alterar a Seção II, do Provimento 63/17, do CNJ, sob a alegação de que o Colégio se preocupa com os efeitos do provimento, tendo em vista o afastamento da atuação jurisdicional na constituição da parentalidade socioafetiva, além da facilidade de ocorrência de irregularidades em casos de adoção. Não obstante, solicitou a alteração sob fundamento de que o provimento ultrapassou a competência legislativa do CNJ, vez que os artigos supracitados retiram o Poder Judiciário da análise de possibilidade dos registros de paternidade ou maternidade socioafetiva.

Ao receber o expediente, o Corregedor Nacional entendeu que o provimento 63 apenas formalizou situação cotidiana. Assim, determinou que se oficiasse às Corregedoras-gerais de Justiça dos Estados e do Distrito Federal, ao Instituto Brasileiro de Direito de Família (IBDFAM), à Associação dos Registradores de Pessoas Naturais (ARPEN-BR) e à Associação dos Notários e Registradores (ANOREG-BR), para que se manifestassem acerca do alegado na inicial.

Diante da análise do pedido, o provimento 83, do Conselho Nacional de Justiça, de 14 de agosto de 2019, acabou por alterar os requisitos na paternidade socioafetiva, do Provimento 63, resolvendo que o reconhecimento da paternidade ou maternidade socioafetiva será autorizado perante os oficiais de registro civil das pessoas naturais, quando se tratar de pessoas acima de 12 anos, e não de qualquer idade, como estabelecido no provimento 63. Além do mais, foi acrescido o artigo 10-A, nos seguintes termos:

Art. 10-A. A paternidade ou a maternidade socioafetiva deve ser estável e deve estar exteriorizada socialmente.

$1^{\circ} \mathrm{O}$ registrador deverá atestar a existência do vínculo afetivo da paternidade ou maternidade socioafetiva mediante apuração objetiva por intermédio da verificação de elementos concretos.

$2^{\circ} \mathrm{O}$ requerente demonstrará a afetividade por todos os meios em direito admitidos, bem como por documentos, tais como: apontamento escolar como responsável ou representante do aluno; inscrição do pretenso filho em plano de saúde ou em órgão de previdência; registro oficial de que residem na mesma unidade domiciliar; vínculo de conjugalidade - casamento ou união estável - com o ascendente biológico; inscrição como dependente do requerente em entidades associativas; fotografias em celebrações relevantes; declaração de testemunhas com firma reconhecida.

$3^{\circ} \mathrm{A}$ ausência destes documentos não impede o registro, desde que justificada a impossibilidade, no entanto, o registrador deverá atestar como apurou o vínculo socioafetivo. 
$4^{\circ}$ Os documentos colhidos na apuração do vínculo socioafetivo deverão ser arquivados pelo registrador (originais ou cópias) juntamente com o requerimento.

Não obstante, foi alterado o $\S 4 .^{\circ}$, do artigo 11 , que antes estipulava a idade do filho superior a doze anos para que o reconhecimento da paternidade ou maternidade socioafetiva dependesse de seu consentimento. A partir das modificações, fica estipulado que será exigido o consentimento do filho para reconhecimento da paternidade ou maternidade socioafetiva, caso tenha menos de 18 anos.

Por fim, o artigo 14 passa a vigorar acrescido de dois parágrafos, que determinam que a inclusão de mais de um ascendente socioafetivo, seja do lado materno ou paterno, deverá tramitar pela via judicial. Na essência, o vínculo familiar trata-se mais de um vínculo de afeto que ligação biológica, o que torna imprescindível destacar o informativo n. 0407, do Superior Tribunal de Justiça, determinando obrigatoriedade ao pagamento de pensão alimentícia quando formado vínculo socioafetivo:

DIREITO CIVIL. ALIMENTOS NA HIPÓTESE DE FORMAÇÃO DE VÍNCULO SOCIOAFETIVO. A esposa infiel não tem o dever de restituir ao marido traído os alimentos pagos por ele em favor de filho criado com estreitos laços de afeto pelo casal, ainda que a adúltera tenha ocultado do marido o fato de que a referida criança seria filha biológica sua e de seu "cúmplice". Isso porque, se o marido, ainda que enganado por sua esposa, cria como seu o filho biológico de outrem, tem-se por configurada verdadeira relação de paternidade socioafetiva, a qual, por si mesma, impede a repetição da verba alimentar, haja vista que, a fim de preservar o elo da afetividade, deve-se considerar secundária a verdade biológica, porquanto a $\mathrm{CF}$ e o próprio $\mathrm{CC}$ garantem a igualdade absoluta dos filhos de qualquer origem (biológica ou não biológica). Além do mais, o dever de fidelidade recíproca dos cônjuges, atributo básico do casamento, em nada se comunica com a relação paternal gerada, mostrando-se desarrazoado transferir o ônus por suposto insucesso da relação à criança alimentada (...) REsp 922.462SP, Rel. Min. Ricardo Villas Bôas Cueva, julgado em 4/4/2013.

A paternidade, em si, trata-se de um fato cultural, que vai além de um fator natural. A família atual não mais se restringe à família biológica, e, nesse trilhar, Paulo Lôbo traz a seguinte lição:

No que respeita aos filhos, a evolução dos valores da civilização ocidental levou à progressiva superação dos fatos de discriminação entre eles. Projetou- 
se, no campo jurídico-constitucional, a afirmação da família como grupo social fundado essencialmente nos laços da afetividade. Encontram-se na CF quatro fundamentos essenciais do princípio da afetividade, constitutivos dessa aguda evolução social da família, máxime durante as últimas décadas do século XXI: a) todos os filhos são iguais independentemente de sua origem; b) a adoção, como escolha afetiva, alçou-se integralmente ao plano da igualdade de direitos; c) a comunidade formada por qualquer dos pais e seus descendentes, incluindo-se os adotivos, tem a mesma dignidade de família, constitucionalmente protegida; d) o direito à convivência familiar, e não a origem genética, constitui prioridade absoluta da criança e do adolescente. ${ }^{9}$

Diante de tudo quanto exposto, torna-se claro que o ordenamento jurídico deve e já está tecendo soluções para que haja respaldo e proteção jurídica às pessoas que estão ou, durante a vida, estiveram ligadas por vínculos de afeto e carinho.

\section{Os fundamentos do direito sucessório}

A Constituição Federal, em seu artigo $5 .^{\circ}$, inciso XXX, bem como o artigo 1.784, do Código Civil, garantem o direito à herança, que se trata de uma transferência de bens e de deveres, não tão simples quanto parece. A sucessão não aparece exclusivamente quando o assunto é direito hereditário. Pode ocorrer tanto entre pessoas vivas, como nos casos de cessão de créditos, quanto em decorrência da morte. Para fins desse trabalho, entretanto, é imprescindível estudo sobre a sucessão proveniente da morte, que é justamente a partir da qual surge o Direito sucessório, um complexo de normas que regulamenta essa transferência de bens e de obrigações de determinada pessoa em razão de sua morte. Maria Helena Diniz conceitua o Direito sucessório como:

O conjunto de normas que disciplinam a transferência do patrimônio de alguém, depois de sua morte, ao herdeiro, em virtude da lei ou de testamento. Consiste, portanto, no complexo de disposições jurídicas que regem a transmissão de bens ou valores e dívidas do falecido, ou seja, a transmissão do ativo e do passivo do de cujus ao herdeiro. ${ }^{10}$

\footnotetext{
9 LÔBO, Paulo. Código Civil Comentado. São Paulo: Atlas, 2003. V. 26, p. 42.

10 DINIZ, Maria Helena apud TARTUCE, Flávio. Direito civil. Direito das sucessões. v. 6. Rio de Janeiro: Forense, 2018, p 2.
} 
Amparado por valores constitucionais, esse ramo do Direito Civil disciplina o destino do que foi deixado pela pessoa natural quando falece. É, no modo mais claro, a possibilidade de dar continuidade ao que seria interrompido pelo fenômeno morte.

\subsection{Função social da herança}

Para maior compreensão, cabe trazer os dizeres de Pablo Stolze Gagliano e Rodolfo Pamplona Filho:

[...] posto em menor medida do que no exercício do direito de propriedade, também a herança possuiu uma função social, porquanto permite uma redistribuição da riqueza do de cujus, transmitida aos seus herdeiros. Observese, ademais, que certos institutos, como o direito de representação, a ser estudado posteriormente, têm um fundamento moral, respaldado no princípio da isonomia e da função social, na medida em que visam a dar um tratamento equânime a herdeiros do autor da herança, poupando-lhes a dupla tristeza da perda de seu ascendente imediatamente direto e também de benefícios potenciais que lhe estariam garantidos, se não tivesse ocorrido o falecimento daquele. ${ }^{11}$

O Direito à herança deve ser estudado e analisado em conformidade com os princípios supracitados, tais como direito de igualdade entre os filhos, cônjuges e companheiros, princípio da afetividade, relacionados com o direito à propriedade e sua função social, vez que a função social é alcançada na medida em que prepondera os interesses sociais em relação aos particulares, atingindo o direito em sua forma plena.

No ramo sucessório, é evidente a existência de um interesse social na preservação desse direito, sendo resultado do princípio da propriedade juntamente à preservação do instituto familiar; destarte, ao se transmitir a herança aos herdeiros, perpetua-se a família, por meio de patrimônios e deveres, atingindo interesses individuais e coletivos.

\subsection{As modalidades de herdeiros do Código Civil}

De acordo com o Código Civil, artigo 1.784 e seguintes, o herdeiro é o sucessor, que será beneficiado de algum modo logo após a morte do de cujus, classificando-os em legítimos e testamentários. Os legítimos são aqueles

Ibid., p. 8 . 
estipulados pelo ordenamento jurídico, pela lei em si, subdivididos em herdeiros facultativos e necessários, amparados pelos artigos 1.845 e 1.846, do Código Civil. Para melhor compreensão, são os descendentes, os ascendentes, o cônjuge e, após julgamento do Supremo Tribunal Federal em maio de 2017, também o companheiro.

Por sua vez, os herdeiros facultativos vão herdar na falta de herdeiros necessários ou em razão de testamento que estabeleça o destino da herança. Por não serem herdeiros reservatários, consoante artigo 1.850, do Código Civil, podem ser excluídos da sucessão, desde que o testador disponha da integralidade de seu patrimônio, sem contemplá-los.

Quando houver herdeiros necessários, a liberdade de testar restringir-se-á somente a $50 \%$ do patrimônio disponível. Se houver somente os facultativos, essa liberdade será plena. Esses herdeiros, por necessária observação, são os colaterais até quarto grau: irmãos, sobrinhos e primos, considerando que os mais próximos excluem os mais distantes, com exceção ao artigo 1.843, do Código Civil, que concede o direito à representação dos filhos dos irmãos, na falta destes.

Os herdeiros testamentários, por seu turno, são aqueles instituídos por meio de testamento, legado ou codicilo. Possuem capacidade testamentária ativa todas a pessoas que quiserem dispor de seus bens por testamento, sendo incapazes os menores de 16 anos, com a ressalva de que, entre 16 e 18 anos, é permitido que a pessoa faça testamento livremente, ainda que sem assistência de seu representante legal, e os desprovidos de discernimento, impossibilitados de expressarem sua vontade em razão de incapacidade mental.

\subsection{Sucessão legítima e parentesco}

O parentesco refere-se às relações jurídicas que há entre indivíduos que mantêm vínculo familiar baseado, principalmente, na afetividade. Flávio Tartuce delimita três modalidades de parentesco:

a) parentesco consanguíneo ou natural - aquele existente entre pessoas que mantêm entre si um vínculo biológico ou de sangue, ou seja, que descendem de um ancestral comum, de forma direta ou indireta. (...)

b) parentesco por afinidade - existente entre um cônjuge ou companheiro e os parentes do outro cônjuge ou companheiro. (...)

c) parentesco civil - decorrente de outra origem, que não seja a consanguinidade ou a afinidade, $(\ldots)^{12}$

TARTUCE, Flávio. Direito Civil. Direito das sucessões. v. 6. Rio de Janeiro: Forense, 2018. 
A última modalidade sempre foi relacionada à adoção; entretanto, com os progressos supramencionados, foram também reconhecidas outras duas formas de parentesco civil: a reprodução assistida heteróloga e a parentalidade socioafetiva, sendo esta fundada na posse do estado de filho, que adquire equivalência com as demais, por reconhecimento do Supremo Tribunal Federal. Isso posto, é imprescindível tratar sobre sucessão legítima, que decorre da norma jurídica, obedecendo à ordem de vocação hereditária. Nesse sentido, enuncia o artigo 1.591, do Código Civil: "São parentes em linha reta as pessoas que estão umas para com as outras na relação de ascendentes e descendentes."; assim, acima, trata-se de ascendente e, abaixo, descendente, variando os graus de parentesco conforme as gerações.

A contagem dos graus referentes ao parentesco por afinidade ocorrerá do mesmo modo, considerando o parentesco por equiparação. Logo, haverá parentesco por afinidade em relação aos ascendentes, estendendo-se até o segundo grau na linha colateral. Assim, discursa Flávio Tartuce:

De todo modo, adiantamos que, com a citada decisão do Supremo Tribunal Federal que, em repercussão geral, equiparou a parentalidade socioafetiva á biológica, a tendência é atribuir amplos direitos sucessórios entre padrastos, madrastas e enteados (Recurso Extraordinário 898.060/SC, Rel. Min. Luiz Fux, j. 21.09.2016, publicado no informativo n. 840 do STF). ${ }^{13}$

A afirmação do direito à multiparentalidade ganhou força jurídica e, por óbvio, seguirá este mesmo ordenamento jurídico.

\section{O direito à sucessão dos ascendentes em caso de multiparentalidade}

Considerando que o ser humano está ligado por laços genéticos, afetivos e ontológicos, o novo fenômeno jurídico, o reconhecimento da multiparentalidade, surge com o objetivo de se alinhar à realidade social, que se encontra em constante mutação, quebrando o paradigma da biparentalidade. Sobre o tema, Belmiro Welter preleciona:

Entendo que, quando se cuida de ação de estado, de direito da personalidade, indisponível, imprescritível, intangível, fundamental à existência humana, como é o reconhecimento das paternidades genética e socioafetiva, não se deve buscar

p. 145 .

13 Ibid., p. 152. 
compreender o ser humano com base no direito registral, que prevê a existência de um pai e uma mãe, e sim na realidade da vida de quem tem, por exemplo, quatro pais (dois genéticos e dois afetivos), atendendo sempre aos princípios fundamentais da cidadania, da afetividade, da convivência em família genética e afetiva e da dignidade humana, que estão compreendidos na condição humana tridimensional. ${ }^{14}$

Desvinculada a função parental da ascendência biológica, a sociedade brasileira tem mostrado que o papel de desenvolvimento dos filhos pode ser exercido por mais de uma figura materna ou paterna, de modo a ser possível se pensar nas relações de multiparentalidade nos mais variados tipos de núcleos familiares. São notórios o desenvolvimento e o reconhecimento ao longo das últimas décadas, vejamos:

APELAÇÃO CIIVEL. AÇÃO DE INVESTIGAÇÃO DE PATERNIDADE. PRESENÇA DA RELAÇÃO DE SOCIOAFETIVIDADE. DETERMINAÇÃO DO PAI BIOLÓGICO AGRAVÉS DO EXAME DE DNA. MANUTENÇÃO DO REGISTRO COM A DECLARAÇÃO DA PATERNIDADE BIOLÓGICA. POSSIBILIDADE. TEORIA TRIDIMENSIONAL. Mesmo havendo pai registral, o filho tem o direito constitucional de buscar sua filiação biológica (CF, $\S 6^{\circ}$ do art. 227), pelo princípio da dignidade da pessoa humana. O estado de filiação é a qualificação jurídica da relação de parentesco entre pai e filho que estabelece um complexo de direitos e deveres reciprocamente considerados. Constitui-se em decorrência da lei (artigos 1.593, 1.596 e 1.597 do Código Civil, e 227 da Constituição Federal), ou em razão da posse do estado de filho advinda da convivência familiar. Nem a paternidade socioafetiva e nem a paternidade biológica podem se sobrepor uma à outra. Ambas as paternidades são iguais, não havendo prevalência de nenhuma delas porque fazem parte da condição humana tridimensional, que é genética, afetiva e ontológica. APELO PROVIDO. (SEGREDO DE JUSTIÇA). (Apelação Cível, No 70029363918, Oitava Câmara Cível, Tribunal de Justiça do RS, Relator: Claudir Fidelis Faccenda, Julgado em: 07-05-2009). Assunto: Direito de Família. Investigação de Paternidade. Filiação biológica. Declaração. Filiação socioafetiva. Pai registral. Manutenção.

O presente caso trata-se de uma ação de investigação de paternidade, com julgamento no ano de 2009, em que o menor, representado por sua genitora,

\footnotetext{
14 WELTER, Belmiro. Teoria tridimensional do direito de família. Porto Alegre: Livraria do advogado, 2009. p. 123.
}

140 • Themis Revista Jurídica • Volume 02 • Número 03 • Jan-Dez 2021 
requer a declaração da filiação biológica, mantendo-se a socioafetiva, já consolidada. O Ministério Público apelou, e o apelo foi provido. Nessa situação, o magistrado entendeu pela não alteração no registro do menor, mantendo-se o nome de apenas um pai, o socioafetivo, em decorrência do tempo de convivência com o requerente.

Por sua vez, no ano de 2012, em ação declaratória de maternidade socioafetiva cumulado com pedido de retificação de assento de nascimento, em que os coautores são filho e madrasta, o desembargador reconheceu o pleito. Nesse caso, os requerentes apelaram da sentença, já que a decisão de $10^{\circ}$ grau não lhes foi favorável; assim, em segunda instância, o desembargador deu provimento para constar no registro de nascimento do filho, concomitantemente com o assento da maternidade biológica, o nome da mãe socioafetiva.

Inúmeros são os precedentes que reconhecem a multiparentalidade, havendo a retificação do registro civil dos filhos socioafetivos. A questão é de suma importância e chegou ao Supremo Tribunal Federal que, por seu turno, julgando o Recurso Extraordinário 898.060/SC, no ano de 2016, decidiu pelo acolhimento da multiparentalidade, já que a existência de uma paternidade socioafetiva não deve prejudicar o filho de buscar ou ter relação com sua paternidade biológica e, assim, ser sujeito passivo de todos os direitos e obrigações decorrentes dessa ligação. Vejamos:

EMENTA: RECURSO EXTRAORDINÁRIO. REPERCUSSÃO GERAL RECONHECIDA. CONFLITO ENTRE PATERNIDADES SOCIOAFETIVA E BIOLÓGICA. PARADIGMA DO CASAMENTO. EIXO CENTRAL DO DIREITO DE FAMÍLIA: (...) PARENTALIDADE PRESUNTIVA, BIOLÓGICA OU AFETIVA. NECESSIDADE DE TUTELA JURÍDICA AMPLA. MULTIPLICIDADE DE VÍNCULOS PARENTAIS. PRINCÍPIO DA PATERNIDADE RESPONSÁVEL (ART. 226, § $7^{\circ}$, CRFB). RECURSO A QUE SE NEGA PROVIMENTO. FIXAÇÃO DE TESE PARA APLICAÇÃO A CASOS SEMELHANTES. 1. (...) 15. Os arranjos familiares alheios à regulação estatal, por omissão, não podem restar ao desabrigo da proteção a situações de pluriparentalidade, por isso que merecem tutela jurídica concomitante, para todos os fins de direito, os vínculos parentais de origem afetiva e biológica, a fim de prover a mais completa e adequada tutela aos sujeitos envolvidos, ante os princípios constitucionais da dignidade da pessoa humana (art. $1^{\circ}$, III) e da paternidade responsável (art. 226, $\S 7^{\circ}$ ). 16. Recurso Extraordinário a que se nega provimento, fixando-se a seguinte tese jurídica para aplicação a casos semelhantes: "A paternidade socioafetiva, declarada ou não em registro público, não impede o reconhecimento do vínculo de filiação concomitante 
baseado na origem biológica, com todas as suas consequências patrimoniais e extrapatrimoniais".

Luiz Fux ${ }^{15}$, em seu voto, fundamentou:

Transportando-se a racionalidade para o Direito de Família, o direito à busca da felicidade funciona como um escudo do ser humano em face de tentativas do Estado de enquadrar a sua realidade familiar em modelos pré-concebidos pela lei. É o direito que deve se curvar às vontades e necessidades das pessoas, não o contrário, assim como um alfaiate, ao deparar-se com uma vestimenta em tamanho inadequado, faz ajustes na roupa, e não no cliente... A partir da Carta de 1988, exige-se uma inversão de finalidades no campo civilístico: o regramento legal passa a ter de se adequar às peculiaridades e demandas dos variados relacionamentos interpessoais, em vez de impor uma moldura estática baseada no casamento entre homem e mulher. (grifo nosso).

Com pauta no entendimento vencedor, o Supremo Tribunal Federal firmou tese no tema 622 , no que concerne à prevalência da paternidade socioafetiva em detrimento da paternidade biológica, no seguinte sentido: “A paternidade socioafetiva, declarada ou não em registro público, não impede o reconhecimento do vínculo de filiação concomitante baseado na origem biológica, com os efeitos jurídicos próprios". Ou seja, duas filiações produzem todos os efeitos jurídicos decorrentes de uma paternidade ordinária. $\mathrm{O}$ vínculo socioafetivo equivale ao biológico e consolida-se a possibilidade de multiparentalidade.

\subsection{Lacuna legal}

Os modelos de famílias evoluíram em velocidade extraordinária. Logo, não obstante o Código Civil Brasileiro de 2002 ter trazido inovação e atualização nos mais diversos temas, não previu as famílias multiparentais. Abriu-se então um precedente de que os Tribunais Estaduais e também o Superior Tribunal de Justiça vêm decidindo sobre tais contendas, tanto em relação ao Direito das Famílias, quanto ao reconhecimento de filiação e quanto ao Direito das Sucessões. Nas palavras de Christiano Cassetari:

A expressão "o pai e a mãe" deverá ser interpretada, novamente, como todos, ou seja, se a menor tiver quatro genitores no seu assento de nascimento, todos eles

15 STF. Supremo Tribunal Federal. Recurso Extraordinário 898.060. 2019. 
serão usufrutuários e administradores dos bens.

Desse forma, os pais devem decidir em comum as questões relativas aos filhos e seus bens, ou seja, no caso da multiparentalidade, a expressão "os pais" deve ser entendida como todos os que estiverem presentes no assento do nascimento... ${ }^{16}$ (grifo nosso)

Logo, questiona-se: o que ocorre, caso o filho venha a falecer antes dos pais, sem que tenha deixado descendentes? Como serão divididos entre esses, os quinhões hereditários? Ainda restam dúvidas para tais questionamentos e não temos decisões judiciais para a hipótese. Nesse seguimento, estabelece o artigo $1.836, \S 2 .^{\circ}$, do Código Civil:

$\mathrm{Na}$ falta de descendentes, são chamados à sucessão os ascendentes, em concorrência com o cônjuge sobrevivente.

$\S 2 .^{\circ}$ Havendo igualdade em grau e diversidade em linha, os ascendentes da linha paterna herdam a metade, cabendo a outra aos da linha materna.

Entretanto, o artigo 1.837, do Código Civil ${ }^{17}$, determina: "Concorrendo com ascendente em primeiro grau, ao cônjuge tocará um terço da herança; caberlhe-á a metade desta se houver um só ascendente, ou se maior for aquele grau." A despeito de todas essas previsões legais e levando em consideração essa lacuna no ordenamento jurídico pátrio, os pais multiparentais, na situação de sucessão de seu filho, teriam direitos aos bens em partes diferentes, havendo desvantagem com o cônjuge ou convivente sobrevivente.

É notório que ainda há carência de atualização de nossa legislação no que concerne aos novos modelos de famílias, e, embora recentemente definidos os termos socioafetividade e multiparentalidade, já é recorrente a existência de ambos na sociedade brasileira. Filhos não são os apenas havidos dentro do casamento, e isso já foi cautelosamente tratado pela Constituição Federal de 1988, em seu artigo 227.

Aquestãodasucessãodosdescendentesprovenientesdemultiparentalidade, ao que tudo indica, acarretará menos discussões, visto que as chances de haver injustiça com os herdeiros, são bem menores. O assunto já é tratado pelo nosso ordenamento jurídico, levando em consideração a própria legislação, decisões que vêm sendo proferidas pelos tribunais e correntes doutrinárias, que utilizam o

CASSETARI, Christiano. Multiparentalidade e parentalidade socioafetiva: efeitos jurídicos. 3. ed. São Paulo: Atlas, 2017.

17 BRASIL. Lei n. 10.406 de 10 de janeiro de 2002. Institui o Código Civil. 
disposto no Código Civil, por analogia.

A partir do momento que um filho é reconhecido, este passa a ter os mesmos direitos que os outros filhos têm, inclusive os sucessórios. Nessa ótica, o Código Civil garante esta igualdade, conforme artigo 1.835: "Na linha descendente, os filhos sucedem por cabeça, e os outros descendentes, por cabeça ou por estirpe, conforme se achem ou não no mesmo grau."; todavia, quando tratamos sobre os direitos de pais em casos de multiparentalidade, em hipótese de sucessão de seus filhos, principalmente na concorrência com o cônjuge ou convivente sobrevivente, fala-se em concorrência em partes iguais. É impossível a mesma divisão estabelecida pelo Código Civil, como supramencionado, quando o assunto são pais multiparentais. Assim, seria o modo justo a divisão por cabeça ou por linha?

Em hipótese de existência de mais de um vínculo materno ou paterno, à linha materna, contando que tenha uma mãe, caberá a metade integral da quota estabelecida, enquanto aos dois pais, metade da quota cabível aos ascendentes, na proporção de metade para cada um, logo, um quarto (1/4) da herança do de cujus. Em concorrência com o cônjuge ou convivente sobrevivente, considerando que este teria direito a $1 / 3$, essa quota seria reduzida, à linha materna, para $1 / 3$, enquanto os pais teriam direito a $1 / 6$ da herança.

O legislador estabelece que a divisão da herança entre os ascendentes será feita por linhas materna e paterna, para se alcançar a igualdade na sucessão; ao se deparar com a hipótese em tela, porém, a divisão atingiria a igualdade, se feita de acordo com o número efetivo de beneficiados. Nesse contexto, preleciona Flávio Tartuce:

O tema deve ser debatido profundamente nos próximos anos. Todavia, aplicandose os princípios da proporcionalidade e da razoabilidade, este autor entende que a herança deve ser dividida de forma igualitária entre todos os ascendentes, sejam biológicos ou socioafetivos...

Outros problemas práticos podem surgir quanto à multiparentalidade, eis que é preciso saber qual será a quota do cônjuge ou convivente concorrendo com mais de quatro avós do falecido, agora incluindo os socioafetivos e os biológicos. Assim, por exemplo, o cônjuge ou convivente pode concorrer com cinco, seis, sete, oito ou mais avós do de cujus. ${ }^{18}$

Conclui-se que, para sanar qualquer dúvida, dar segurança jurídica e

\footnotetext{
18 TARTUCE, Flávio. Direito Civil. Direito das sucessões. v. 6. Rio de Janeiro: Forense, 2018, p. 218-219.
} 
escapar de possíveis injustiças em razão da aplicação da norma infraconstitucional, é necessário que haja alteração no disposto legal, para que abranja todas as famílias e eventuais necessidades de utilização do Direito sucessório em que serão chamados à sucessão os ascendentes, em concorrência com o cônjuge sobrevivente.

\section{Considerações finais}

A sociedade e as famílias passaram por inúmeras e profundas alterações ao longo das últimas décadas, e, consequentemente, este ramo do Direito sentiu necessidade de evolução, visto que pouco se discutia acerca do reconhecimento de outras formas de conjugabilidade ao lado da família legítima ou sobre a paridade de direito entre filhos de qualquer origem, muito menos sobre a sucessão legítima dos ascendentes.

Vimos que a horizontalização das normas que protegem as pessoas tem necessidade de ser aplicada entre os particulares e que os antigos princípios de Direito de Família foram exterminados, surgindo outros, de acordo com uma proposta de constitucionalização.

Com respaldo nos princípios da dignidade da pessoa humana, da solidariedade familiar, da igualdade entre os filhos, da igualdade entre cônjuges e companheiros, igualdade na chefia familiar, função social da família e da afetividade, adentramos no ramo do Direito das Sucessões, analisando o direito à herança, com ênfase no direito de igualdade entre os filhos, cônjuges e companheiros, relacionados ao direito à propriedade e sua função social.

Restou evidente a existência de um interesse social na preservação desse direito; desse modo tratamos sobre sucessão legítima e parentesco, concluindo que a contagem dos graus referentes ao parentesco por afinidade ocorrerá conforme estabelecido no Código Civil, considerando o parentesco por equiparação, havendo, assim, parentesco por afinidade em relação aos ascendentes, estendendose até o segundo grau na linha colateral.

Por fim, adentramos no direito à sucessão dos ascendentes em caso de multiparentalidade, tratando sobre o reconhecimento de mais de um vínculo paterno ou materno simultaneamente, como um grande fenômeno jurídico, em que foi desvinculada a função parental da ascendência biológica, por meio do julgamento de Recurso Extraordinário pelo Tribunal Pleno do Supremo Tribunal Federal.

Tendo em vista que, com a constante evolução da sociedade, vem a necessidade de amparo jurisdicional para a resolução de possíveis conflitos, estudamos a lacuna legal existente quanto à sucessão dos ascendentes em caso de 
multiparentalidade, questionando como se daria a sucessão, caso o filho venha a falecer antes dos pais, sem que tenha deixado descendentes.

Embora haja determinações quanta à partilha da herança no Código Civil, ainda restam dúvidas sobre como proceder, por conta, justamente, da carência de atualização de nossa legislação no que concerne aos novos modelos de famílias.

Logo, para sanar tais dúvidas, se desvencilhar de injustiças e inseguranças jurídicas, é necessário que haja alteração em nosso ordenamento jurídico, abrangendo todos os modelos de famílias já constantes em nossa sociedade, com ênfase no Direito sucessório, em que serão chamados à sucessão os ascendentes, em concorrência com o cônjuge sobrevivente.

\section{Referências bibliográficas}

BRASIL. Constituição Da República Federativa Do Brasil De 1988. Casa Civil. Disponível em: http://www.planalto.gov.br/ccivil_03/constituicao/ constituicao.htm. Acesso em: 28 set. 2020.

BRASIL. Lei n. 10.406 de 10 de janeiro de 2002. Institui o Código Civil. Disponívelem:http://www.planalto.gov.br/ccivil_03/leis/2002/110406compilada. htm. Acesso em: 28 set. 2020.

CASSETTARI, Christiano. Multiparentalidade e parentalidade socioafetiva: efeitos jurídicos. 3. ed. rev., atual. e ampl. São Paulo: Atlas, 2017.

CNJ. Conselho Nacional de Justiça. Provimento n. 63 de 14 de novembro de 2017. Disponível em: https://atos.cnj.jus.br/atos/detalhar/2525. Acesso em: 27 set. 2020.

DIAS, Maria Berenice. Amor não tem idade. Portal Jurídico Investidura, Florianópolis/SC, 12 Jan. 2009. Disponível em http://investidura.com.br/ biblioteca-juridica/artigos/direito-civil/2471-amor-nao-tem-idade. Acesso em: 25 maio 2019.

. Manual de direito das famílias. [livro eletrônico] 10 ed. São Paulo: Editora Revista dos Tribunais, 2016.

DINIZ, Maria Helena. Curso de Direito Civil Brasileiro: Direito de Família. 17. ed. São Paulo: Saraiva, 2012, v. 05. 
GAGLIANO, Pablo Stolze; PAMPLONA FILHO, Rodolfo. 7. ed. Novo Curso de Direito Civil: Direito de Família. São Paulo: Saraiva, 2011, v. 06.

LÔBO, Paulo Luiz Netto. Princípio da Solidariedade Familiar. 2013. Disponível em https://jus.com.br/artigos/25364/principio-da-solidariedade-familiar. Acesso em: 23 maio 2019.

MADALENO, Rolf. Filhos do Coração. Revista Brasileira de direito de família, n. 23. Porto Alegre: Síntese, abr./maio, 2004.

REALE, Miguel. Função Social da Família. 2003. Disponível em http://www. miguelreale.com.br/artigos/funsoc.htm. Acesso em: 12 jul. 2019.

RIBEIRO, GL et al. Repercussões práticas das novas famílias na pós-modernidade. Direito e Sociedade. Revista de Estudos Jurídicos e Interdisciplinares. Centro Universitário Padre Albino, Curso de Direito. Catanduva: Centro Universitário Padre Albino, Curso de Direito, 2006, v. 13.

SARLET, Ingo Wolfgang. A eficácia dos direitos fundamentais. 5. ed. Porto Alegre: Livraria do Advogado, 2005.

STF. Supremo Tribunal Federal. Recurso Extraordinário 898.060. 2019. Disponível em: https://www.jusbrasil.com.br/processos/56375271/processo-n898060-do-stf. Acesso em: 27 set. 2020.

TARTUCE, Flávio. Direito Civil. Direito das Sucessões. 11. ed. rev., atual. e ampl. Rio de Janeiro: Forense; São Paulo: Método, 2018, v. 6.

Direito Civil. Direito de Família. 8. ed. Rio de Janeiro: Forense; São Paulo: Método, 2013, v. 5.

WELTER, Belmiro. Teoria tridimensional do direito de família. Porto Alegre: Livraria do advogado editora, 2009. 